\title{
Disfunciones en primates no humanos: la discapacidad desde una perspectiva evolutiva
}

\author{
Dysfunctions in non-human primates: Disability from an evolutionary \\ perspective
}

\begin{abstract}
Resumen
Se presenta una revisión sistemática y actualizada de la literatura sobre discapacidad en primates no humanos. La información obtenida muestra que en diversas especies de primates los individuos con malformaciones y otras anormalidades, congénitas o adquiridas, tienen una importante flexibilidad conductual que en muchas ocasiones les permite sobrevivir y reproducirse a pesar de sus limitaciones. En algunos casos se ha observado que los individuos con discapacidad reciben cuidados por parte de sus congéneres, particularmente las crías e infantes. Las madres también muestran flexibilidad conductual para adaptarse a las necesidades y ritmos de los individuos afectados. El cuidado en la discapacidad aparece como un rasgo importante del comportamiento social de los primates no humanos. Por lo anterior, se plantea una crítica a la teoría aun prevaleciente del darwinismo social y su ideología de un mundo que mejora con base en la competencia y supervivencia solo de los más aptos, situación que impacta negativamente en el trato a personas con discapacidad.
\end{abstract}

\section{Palabras clave}

Evolución, cuidado, discapacidad, flexibilidad conductual, darwinismo social.

\begin{abstract}
A systematic and updated review of the literature on disability in non-human primates is presented. The information obtained shows that in several primate species, individuals with malformations and other abnormalities, congenital or acquired, have an important behavioral flexibility that in many cases allows them to survive and reproduce despite their limitations. In some cases, it has been observed that individuals with disabilities are cared for by their peers, particularly the offspring and infants. Mothers also show behavioral flexibility to adapt to the needs and rhythms of affected individuals. Caregiving in disability appears as an important feature of the social behavior of non-human primates. Therefore, a critique of the still prevailing theory of social Darwinism and its ideology of a world that improves based on competition and survival only of the fittest, a situation that has a negative impact on the treatment of people with disabilities, is raised.
\end{abstract}

\section{Keywords}

Evolution, caregiving, disability, behavioral flexibility, social Darwinism.

\author{
Ignacio García Madrid \\ <ngarma@yahoo.com>
}

Universidad Autónoma del Estado de Morelos. México

\section{Juan Carlos Serio-Silva \\ <juan.serio@inecol.mx>}

Instituto de Ecología, A. C. (INECOL) México

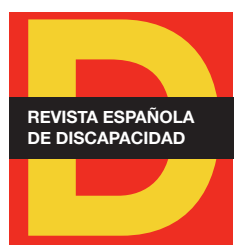

Para citar:

García, I. y Serio-Silva, J. C. (2021). Disfunciones en primates no humanos: la discapacidad desde una perspectiva evolutiva. Revista Española de Discapacidad, 9(1), pp. 33-57.

Doi: <https://doi.org/10.5569/23405104.09.01.02>

Fecha de recepción: 20-08-2020 Fecha de aceptación: 26-05-2021 


\section{Introducción ${ }^{1}$}

Diversos estudios han señalado notables diferencias en el trato a las personas con discapacidades, en función del tiempo histórico, cultura y sitio del evento. Aguado (1995) señaló que para la prehistoria se pueden detectar dos actitudes hacia la enfermedad y las anormalidades: la actitud activa, ligada a la terapéutica pre-técnica y la magia, procuraba remediar las enfermedades y la discapacidad, en tanto que la actitud pasiva, relacionada con el animismo, donde la visión del mundo atribuye males y enfermedades a entidades espirituales ajenas al poder humano, era de rechazo total, con el infanticidio oscilando entre la necesidad y el egoísmo en muchos pueblos animistas ${ }^{2}$ (Aguado, 1995). Los hallazgos de esqueletos humanos prehistóricos de individuos que sobrevivieron hasta edades juveniles y adultas con malformaciones congénitas o graves disfunciones por enfermedades y accidentes, apuntan a un activo apoyo de la comunidad para su supervivencia, proporcionando nuevos datos para el debate sobre las dimensiones culturales de la enfermedad y discapacidad en esas épocas (Milella et al. 2015; Tilley, 2015; Oxenham et al. 2009). En una descripción inicial, la Organización Mundial de la Salud (2011, p. 7) define a la discapacidad como:

"Un término genérico que engloba deficiencias, limitaciones de actividad y restricciones para la participación. La discapacidad denota los aspectos negativos de la interacción entre personas con un problema de salud (como parálisis cerebral, síndrome de Down o depresión) y factores personales y ambientales (como actitudes negativas, transporte y edificios públicos inaccesibles, y la falta de apoyo social".

Sin embargo, bajo estos preceptos es indudable que dentro de la discapacidad se deben considerar los determinantes sociales de la salud y la enfermedad que afectan diferencialmente a individuos y poblaciones de acuerdo con su estatus económico, social, laboral, racial, de género, lugar de residencia, etcétera, y que hacen a cada sujeto más o menos propenso a accidentes, enfermedades y vejez prematura o con mayor deterioro físico y cognitivo, es decir, a discapacidad temporal o permanente (PAHO, 2012).

"Cuando se habla de discapacidad no se hace referencia a un asunto individual ni privado, al contrario, se habla de un problema colectivo y público, en tanto que se hace referencia a las barreras o limitaciones construidas dentro y por la sociedad -en sentido amplio-, que afectan la participación plena y el disfrute de derechos en igualdad de condiciones de las personas con deficiencias físicas, mentales, intelectuales o sensoriales" (Conadis, 2012, p. 6).

La "Clasificación Internacional del Funcionamiento, de la Discapacidad y de la Salud" (CIF) (OMS, 2001) presenta un nuevo marco conceptual para comprender y atender el funcionamiento corporal, actividad y participación social. Desde este marco, las deficiencias, limitaciones de actividad y participación social de las personas implican un importante componente social. La CIF refleja la transición del modelo médico rehabilitador o individual, donde la discapacidad se atribuye al individuo como una variación negativa de la norma biológica (Hahn, 1985; Quinn y Degener, 2002; citados por Pérez y Chhabra, 2019) al modelo social promovido desde los años cincuenta del siglo pasado por movimientos sociales en Europa, Estados Unidos y Canadá, que lucharon contra la segregación de las personas con discapacidad (Thomas, 2002; citado por Pérez y Chhabra, 2019). Para Seco (s/f) investigar sobre discapacidad implica la necesidad de establecer un eje pasado-presente-futuro que visibilice cómo se construyen los conceptos sobre discapacidad en función de diversos ambientes socioculturales en diferentes momentos históricos,

1. Agradecimientos: a los/as revisores/as anónimos/as de REDIS. Sus generosas observaciones y sugerencias a la primera versión de este trabajo enriquecieron el contenido actual.

2. Los habitantes de las Nuevas Hébridas (archipiélago de las Islas Vanuatu, en el océano Pacífico Sur) no solo sacrificaban al infante malformado sino también a su madre (Scheerenberger, 1984, citado por Aguado, 1995). 
"De esta manera, se puede analizar el proceso, los cambios sociales y consideración social de las personas con algún tipo de discapacidad, dentro del grupo de aquellas que se sitúan fuera de la "norma" en cada uno de esos momentos [...]" (Seco, s/f: s/p).

La importancia del eje temporal propuesto por Seco es fundamental para abordar el estudio de la discapacidad. Como es bien sabido, los humanos como especie y como individuos vamos cambiando progresivamente, y con ello vamos generando diversas modificaciones físicas y sociales en nuestra dinámica de adaptación permanente al entorno. La lenta evolución biológica junto a los acelerados cambios sociales humanos generan una mayor complejidad para la vida humana. Por lo anterior, el presente trabajo aborda una reflexión integral sobre la información disponible y la posibilidad de abordar a la discapacidad desde una perspectiva evolutiva y comparada. Lo anterior particularmente revisando las estrategias conductuales, individuales y sociales, de primates no humanos, cuando algunos individuos presentan malformaciones o disfunciones. Es con base en lo anterior, que se plantea una crítica a la ideología aun prevaleciente de "la sobrevivencia de los más aptos" que para este aspecto en particular enarboló la corriente del darwinismo social.

\section{Método}

Considerando la perspectiva corporal (estructuras y funciones) y ambiental/contextual de la salud y la discapacidad (OMS, 2001), nos preguntamos acerca de las posibilidades de supervivencia en la naturaleza de sujetos con deficiencias o limitaciones de actividad. Por lo anterior, el objetivo de este trabajo fue buscar pruebas a nivel conductual de sociedades de primates no humanos que podrían estar eliminando o discriminando a los sujetos con malformaciones físicas o disfunciones conductuales. Se recurrió al método de revisión sistemática de literatura (Beltrán, 2005). El análisis de los resultados fue cualitativo.

El 3 de marzo de 2021 se realizó una búsqueda de literatura científica, en español e inglés, sobre discapacidad en animales no humanos, sin acotación temporal, en los buscadores Dialnet (en español), Google Académico (en español e inglés), Scielo, Springer Link y Refseek (en estos últimos en inglés). Los términos iniciales de la búsqueda fueron: "discapacidad, animales no humanos". Dado que estos términos no arrojaron resultados, se acotaron a "discapacidad, primates no humanos", y posteriormente se acotaron aún más, usando "discapacidad, chimpancés", "discapacidad, bonobos", "discapacidad, gorilas" y "discapacidad, orangutanes". Los términos en inglés fueron: "disability, impairment, non-human animals", "disability, impairment, non-human primates", "disability, impairment, chimpanzees", "disability, impairment, bonobos", "disability, impairment, gorillas" y "disability, impairment, orangutans". Los términos "non human primates" y "chimpanzees" también arrojaron algunos artículos sobre especies de monos. Se seleccionaron los estudios que describieran: 1) las formas de discapacidad, 2) el posible origen de la(s) discapacidad(es), 3) el comportamiento de los individuos con discapacidad, y 4) el comportamiento de los congéneres hacia los individuos con discapacidad. Asimismo, fueron excluidos los siguientes estudios: 1) prevalencias de enfermedades o lesiones que no tuvieran información sobre conducta, 2) genética y/o fisiología de enfermedades discapacitantes, 3) rehabilitación mediante modelos animales, 4) estudios sobre envejecimiento de animales no humanos sin referencias a discapacidad, 5) estudios sobre el uso de animales de asistencia por personas con discapacidad, y 6) estudios de ética sobre el trato a animales no humanos. En los trabajos selecciona- 
dos se revisó la literatura citada para incorporar otros estudios que cumplían con los criterios de selección pero que no habían sido detectados por los buscadores ya mencionados. Las principales observaciones y las conclusiones de cada estudio se clasificaron y agruparon para su comparación mediante los siguientes rubros: 1) especie, 2) vida libre o cautiverio, y 3) discapacidad congénita o adquirida.

\section{Resultados}

La búsqueda en español en las bases de datos online no arrojó ningún trabajo, en tanto que en inglés se colectaron 23 artículos. A estos artículos se sumaron 10 trabajos más extraídos de la literatura citada en los primeros artículos colectados, totalizando 33 trabajos, de los cuales 21 son artículos, 3 capítulos de libros, 1 tesis doctoral, 2 tesis de maestría, 3 notas, 2 reportes breves y una comunicación corta. El cuadro 1 resume las especies estudiadas, el número de trabajos por especie, el origen de las discapacidades, las condiciones de vida y los lugares de estudio.

\begin{tabular}{|c|c|c|c|}
\hline $\begin{array}{c}\text { Número de } \\
\text { trabajos }\end{array}$ & Especie & $\begin{array}{c}\text { Origen de la } \\
\text { discapacidad }\end{array}$ & Condiciones de vida/lugares de estudio \\
\hline 14 & $\begin{array}{l}\text { Chimpancés } \\
\text { Pan troglodytes }\end{array}$ & $\begin{array}{l}\text { Adquirida: } 12 \text { trabajos } \\
\text { Congénita: } 2 \text { trabajos }\end{array}$ & $\begin{array}{l}11 \text { trabajos en vida libre: Budongo, Uganda; PNV, } \\
\text { Rwanda; Mahale, Tanzania; Bossou, Guinea; } \\
\text { Sebitoli KNP, Uganda. } \\
3 \text { trabajos en cautiverio: Chester Zoo, UK; Lincoln } \\
\text { Park Zoo, Chicago; Kumamoto Sanctuary, Kyoto } \\
\text { University. }\end{array}$ \\
\hline 12 & $\begin{array}{l}\text { Macacos japoneses } \\
\text { Macaca fuscata }\end{array}$ & $\begin{array}{l}\text { Congénita: } 11 \text { trabajos } \\
\text { Adquirida: } 1 \text { trabajo }\end{array}$ & $\begin{array}{l}11 \text { trabajos en vida libre: Awajishima; Nagano } \\
\text { Prefecture; Japón. } \\
1 \text { trabajo en cautiverio: Primate Research Institute, } \\
\text { Kyoto University. }\end{array}$ \\
\hline 2 & $\begin{array}{l}\text { Bonobos } \\
\text { Pan paniscus }\end{array}$ & Adquirida: 2 trabajos & $\begin{array}{l}\text { Vida libre: Wamba, Zaire y Wamba, LSR, RD del } \\
\text { Congo. }\end{array}$ \\
\hline 1 & Gorilas Gorilla gorilla & Adquirida & Vida libre \\
\hline 1 & $\begin{array}{l}\text { Gibones } \\
\text { Nomascus leucogenys }\end{array}$ & Adquirida & Cautiverio: Lincoln Park Zoo, Chicago, Illinois. \\
\hline 1 & $\begin{array}{l}\text { Macaco de Sri Lanka } \\
\text { Macaca sinica }\end{array}$ & Adquirida & Vida libre: Polonnaruwe, Sri Lanka. \\
\hline 1 & $\begin{array}{l}\text { Mono rhesus } \\
\text { Macaca mulatta }\end{array}$ & Inducida por experimento & $\begin{array}{l}\text { Cautiverio: Center for Primate Biology, University of } \\
\text { California. }\end{array}$ \\
\hline 1 & \begin{tabular}{|l|} 
Monos africanos Colobus \\
guereza; Piliocolobus \\
tephrosceles; Cercopithecus \\
ascanius; Lophocebus albigena \\
\end{tabular} & Adquirida & Vida libre: Kibale, Uganda \\
\hline 1 & Babuinos Papio anubis & Congénita & Vida libre: Kibale, Uganda. \\
\hline 1 & $\begin{array}{l}\text { Babuinos chacma } \\
\text { Papio ursinus }\end{array}$ & Adquirida & Vida libre: TMNP, Península del Cabo, Sudáfrica) \\
\hline 1 & Monos araña Ateles geoffroyi & Adquirida & Vida libre: Santa Rosa, Costa Rica. \\
\hline
\end{tabular}

Fuente: elaboración propia. 


\subsection{Perspectivas de estudio de la discapacidad en primates no humanos}

Destacan la tesis doctoral de Emma Jane Stokes con chimpancés y la tesis de maestría de Sara Elizabeth Turner con macacos japoneses, ambas publicadas en 1999, por abordar las lesiones y las anomalías congénitas en primates no humanos desde perspectivas ecológicas y evolutivas. Antes de estas tesis algunos trabajos abordaron la discapacidad en Macaca fuscata (Nakamichi et al., 1983; Nakamichi, 1986; Nakamichi et al. 1997), Pan paniscus (Kano, 1984), Ateles geoffroyi (Chapman y Chapman, 1987) y Macaca sinica (Dittus y Ratnayeke, 1989), así como referencias a individuos lesionados o con malformaciones congénitas y las repuestas de sus congéneres (Fedigan y Fedigan, 1977; Boesh, 1991a, Byrne y Byrne, 1991; Quiatt et al. 1994; Reynolds et al. 1996; citados por Stokes, 1999). De acuerdo con Turner (1999) las investigaciones publicadas en inglés en los últimos 40 años se habían centrado en la morfología y dinámica poblacional asociadas con las malformaciones (Itani et al. 1963; Furuya, 1966; Iwamoto, 1967; Tanaka y Nigi, 1967; Iwamoto y Hirai, 1970; Yoshiro et al. 1979; Homma, 1980; Yoshiro, 1980; Nakamichi et al. 1983; Nakamichi, 1986; Minezawa et al. 1990; Nakamichi et al. 1997; citados por Turner, 1999), con poca exploración de la influencia de la discapacidad en el comportamiento social, evolución y ecología de las especies de primates, solo con algunas excepciones (para M. fuscata: Fedigan y Fedigan, 1977; Nakamichi et al., 1983; Nakamichi, 1986; citados por Turner, 1999).

Stokes (1999) estudió las habilidades alimenticias y el efecto de las lesiones causadas por trampas en chimpancés de Budongo, Uganda. Con base en la psicología de la salud en humanos, esta autora determinó que las lesiones se pueden medir en tres niveles diferentes: deterioro o deficiencia (impairment), discapacidad (disability) y minusvalía (handicap) (Stokes, 1999:50), donde cada nivel de la(s) lesión(es) tendrán repercusiones en la sobrevivencia y reproducción de los individuos y de sus poblaciones. De acuerdo con Wood (1980, citado por Stokes, 1999), estos conceptos se definen de la siguiente manera:

- Impairment: cualquier pérdida o anomalía de la estructura o función psicológica, fisiológica o anatómica (debida o no a una enfermedad, siempre que se exteriorice).

- Disability: cualquier restricción o falta (resultante de un impaiment) de la capacidad para realizar una actividad dentro del rango considerado normal para un ser humano en su entorno. Para Stokes (1999) es claro que la discapacidad no es simplemente la consecuencia de la enfermedad, sino una interacción con hábitos, formación, habilidades y expectativas de los individuos.

- Handicap: desventaja para un individuo determinado, a menudo (aunque no siempre) como resultado de un impairment o disability que limita o impide al sujeto individuo cumplir con cierto rol normal según su edad, su sexo y factores sociales o culturales.

"Para estos chimpancés, es evidente que existen costos potencialmente elevados derivados de las lesiones, y que la clave para sobrevivir debe estar en superar estos costos. Además, la naturaleza y el alcance de las lesiones varían de un sujeto a otro, y esto inevitablemente influirá en el comportamiento. Una consecuencia probable de estas lesiones parecería ser la dificultad para alimentarse, específica de los alimentos que requieren un grado de procesamiento manual. Sin embargo, puede ser que los chimpancés sean capaces de compensar parcial o totalmente sus lesiones y que, como resultado, se minimice el efecto incapacitante de la lesión en la habilidad para alimentarse y la operación de tales lesiones como factores selectivos en la competencia intraespecífica" (Stokes, 1999, p. 52, traducción propia).

Es a partir de ello que Stokes (1999) se planteó evaluar en una sociedad de chimpancés la relación directa entre el nivel de impairment con la disability/handicap de los individuos en su entorno natural y sin las variables 
culturales de las sociedades humanas. Los resultados de este estudio arrojaron que los chimpancés emplean una amplia gama de habilidades en la alimentación, lo que refleja la variación en su entorno y en su dieta. Los chimpancés utilizan técnicas de alimentación en varias etapas, con coordinación bimanual y comportamiento jerárquico en la organización general. Los individuos sanos muestran una estandarización considerable en su alimentación con preferencia por ciertas técnicas, con una variedad de posturas y posiciones dinámicas de alimentación para acceder a áreas específicas de comida y aumentar su disponibilidad relativa. Para los sujetos lesionados, incluso con las lesiones más graves, no hubo una disminución en la eficiencia de la alimentación y no inventaron soluciones novedosas para tareas familiares, solo modificaban su repertorio existente para solucionar sus lesiones, compartiendo la organización, a nivel de programa, observada en los individuos sin lesiones y compensando la discapacidad a nivel de acciones individuales. No obstante, las limitaciones físicas impuestas por la extremidad lesionada redujeron considerablemente la coordinación bimanual y maniobrabilidad en el árbol, con posibles implicaciones negativas a largo plazo (Stokes, 1999).

Por su parte, Turner (1999) investigó aspectos conductuales de macacos japoneses (Macaca fuscata) en vida libre que poseían malformaciones congénitas en las extremidades, y su relación con la inversión en el cuidado materno a infantes. Desde una perspectiva ecológica-evolutiva, esta autora encontró poca investigación sobre cómo las enfermedades y lesiones influyen en la aptitud reproductiva. La autora propone que la variedad y frecuencia de patologías y lesiones en las poblaciones silvestres (actualmente y en el pasado), deben influir en la evolución a través de la selección natural. Derivado de lo anterior se identifica que la influencia de la discapacidad o deterioro físico permanente en la capacidad reproductiva es poco comprendida, a pesar de que la discapacidad por causa de malformaciones congénitas es análoga a la enfermedad, y en términos de selección natural puede obstruir funciones normales como la locomoción, obtención de alimentos, apareamiento y crianza de infantes. Esta misma reflexión sugiere que la falta general de investigación con perspectiva evolutiva sobre enfermedades, lesiones y discapacidades en primates no-humanos, pudiera estar reflejando en parte una suposición simple: las respuestas sociales a los animales con discapacidad serán negativas (Darwin, 1871; citado por Turner, 1999). Para llegar a esa conclusión, Turner (1999) estudió 12 díadas madre-infante de M. fuscata en libertad, en Isla Awaji, Japón. En el grupo de macacos había tanto infantes como madres con malformaciones congénitas en las extremidades. Las malformaciones congénitas en las extremidades ocurrían en aproximadamente 14,2 \% de la población estudiada, con implicaciones para el comportamiento y la conservación de la especie en su hábitat natural. Las madres con y sin discapacidad no mostraron diferencias significativas en los presupuestos de actividad general y las diversas interacciones madre-infante, pero fue evidente que las madres con discapacidad acicalan a sus hijos significativamente más que sus contrapartes sin discapacidad. La discapacidad de la madre o del infante no afectó el contacto madre-hijo. Las madres de infantes con extremidades malformadas evitaban los comportamientos normales de agarre, cargando a sus hijos durante la lactancia y la locomoción significativamente más tiempo que otras madres. Las altas frecuencias de estrechamiento de los infantes al área ventral de sus madres sugieren que las madres de infantes con extensas malformaciones pueden estar invirtiendo más para facilitar la supervivencia de sus hijos, y las malformaciones congénitas en las extremidades parecen estar influyendo en el comportamiento maternal en esta población.

\subsection{Estudios en macacos japoneses}

Masayuki Nakamichi es un investigador que ha estado estudiando la discapacidad de $M$. fuscata de Isla Awaji desde la década de 1980, y en uno de sus estudios reportó el desarrollo conductual de un infante 
macho sin manos y con las patas traseras deformadas, comparando esta situación con infantes normales (Nakamichi, 1983). En las primeras semanas de vida, la cría con malformaciones no podía moverse sola y dependía casi por completo de su madre. Alrededor del primer mes de vida fue capaz de arrastrarse con los codos de las extremidades anteriores y las patas traseras deformadas, después del sexto mes de vida logró caminar bípedo -de manera inestable- sobre sus patas traseras. Su capacidad locomotora fue esencialmente inferior a la de los infantes normales durante el primer año de vida. En cuanto a las interacciones sociales, los infantes normales aumentaron estas con infantes de su misma edad o con jóvenes a través de comportamientos activos similares al juego, mientras que el infante con malformaciones congénitas en las extremidades se relacionó particularmente con adultos a través de conductas como el contacto corporal pasivo. La cría con discapacidad era cuidada por su madre con más frecuencia que otras madres lo hacían con sus infantes. Debido a las extremidades malformadas, la cría no pudo aferrarse a su madre de la misma manera que las crías normales (con las cuatro extremidades). La madre compensó suficientemente las deficiencias de la cría manteniéndolo en una posición ventro-ventral con la cabeza en su pecho y una o ambas manos cubriendo levemente su espalda cada vez que él mordía un pezón hasta los dos meses de edad, y sosteniéndolo continuamente con un brazo en una posición ventroventral o dorsal mientras caminaba sobre tres extremidades. Después que la cría con discapacidad pudo moverse sobre sus codos y pies, rara vez se observó a su madre cargarlo en el área de alimentación. Sin embargo, cuando el grupo se movía por el bosque, esta cría siempre era transportada por su madre en la forma descrita anteriormente. Desde de los cinco meses de edad empezó a seguir a su madre por sí misma con marcha bípeda, su madre se detenía a esperar que se acercara cuando el individuo estaba a más de 20 o 30 m de ella, siempre que el grupo viajaba o se movía rápido, la madre cargaba a este infante con malformaciones congénitas en las extremidades, pero después de los 10 meses de edad, nunca se le vio en brazos su madre (Nakamichi, 1983).

Estos resultados concuerdan con Berkson (1970, 1973, 1977, citado por Nakamichi, 1983) quien llevó a cabo experimentos en macacos, y observó a una madre proporcionar cuidados compensatorios a su cría ciega en el período temprano. También se detectó en esa oportunidad a un animal macho ciego, cuya madre murió durante su segundo año de vida, aislarse socialmente, lo que sugiere que un fuerte vínculo madre-hijo en primates superiores puede compensar -hasta cierto punto- los defectos de la cría en una situación de cautiverio o en libertad (Nakamichi, 1983). Por otra parte, el infante con malformaciones congénitas en las extremidades adquirió patrones locomotores particulares, como la marcha bípeda, que funcionaba de forma compensatoria para sus defectos y le permitió expandir sus interacciones con su entorno físico y social. Una ventaja para la supervivencia de este infante con discapacidad pudo ser la abundancia de comida y pocos depredadores en su ambiente (Nakamichi, 1983).

Fedigan y Fedigan (1977, citados por Nakamichi, 1983) investigaron a un infante de M. fuscata con daño cerebral extenso en un recinto abierto y encontraron que los miembros del grupo eran muy tolerantes a su falta de respuestas sociales apropiadas o su reacción confusa a las amenazas, y aceptaron su comportamiento anormal. En el caso reportado por Nakamichi (1983), la cría con discapacidad mostró expresiones faciales y posturas adecuadas, y nunca se observó que realizara una conducta comunicativa inapropiada, lo que podría haberle permitido su desarrollo social, con lo que sus deformidades y locomoción distintiva pueden no representar una discapacidad dentro del grupo observado en Awaji. Nakamichi (1983) discute que la relación entre el infante con discapacidad y algunos de los miembros del grupo reflejan ciertos rasgos característicos de las relaciones sociales y estructura de su grupo. Comparado con otros grupos de $M$. fuscata en libertad (Koyama y Fujii, 1980, citados por Nakamichi, 1983), las distancias interindividuales en el grupo Awajishima eran más cortas y sus interacciones menos agonistas. Relaciones sociales íntimas y tole- 
rantes entre los miembros del grupo Awajishima podrían constituir un factor de fondo para la supervivencia del infante con discapacidad durante al menos el primer año de vida (Nakamichi, 1983).

En 1986, Nakamichi reportó sus comparaciones de la locomoción e interacciones madre-hijo de un infante de $M$. fuscata gravemente malformado (sin pies y manos con solo dos dedos), un infante levemente malformado (pies normales y manos con solo dos dedos) y un infante normal. El infante con malformaciones congénitas graves en las extremidades tenía más retraso en el desarrollo de la postura y la locomoción que los otros infantes; sin embargo, desarrolló patrones locomotores adecuados a sus defectos. Los tres infantes pasaron aproximadamente la misma cantidad de tiempo en contacto con sus madres. Se mantuvo un alto contacto madre-hijo de los infantes con malformaciones congénitas en las extremidades porque sus madres estaban muy atentas, los cargaban y sostenían. Las madres criaron a sus infantes con discapacidad a pesar de que las crías carecían del movimiento necesario para aferrarse (Nakamichi, 1983).

En 1997, Nakamichi y colaboradores reportaron su examen de las tasas de natalidad y mortalidad de crías con malformaciones congénitas en las extremidades en el grupo de M. fuscata en Awajishima. De las 606 crías nacidas entre 1978 y 1995, el 14,2 \% (86 sujetos) tenían malformaciones. La proporción macho-hembra no difirió entre crías con malformaciones congénitas en las extremidades y crías normales. La mayoría de los grupos de parentesco incluían hembras que dieron a luz crías con malformaciones al menos una vez. La tasa de mortalidad durante el primer año después del nacimiento de los lactantes con malformaciones congénitas en las extremidades $(28,2 \%)$ fue significativamente más alta que la de los lactantes normales (10\%). Sin embargo, esto indica que más del $70 \%$ de las crías con malformaciones congénitas en las extremidades pudieron sobrevivir durante el primer año de vida, a pesar de no poder aferrarse al ventrum de su madre debido a sus deformidades. El hallazgo indica que el cuidado materno es suficiente para permitir que los infantes con malformaciones sobrevivan durante las primeras etapas del desarrollo y que el aferramiento de la cría no es necesario para el cuidado materno (Nakamichi et al. 1997).

Por otra parte, Turner et al. (2005), reportaron que su estudio de la relación entre el comportamiento materno y la discapacidad infantil en 12 díadas madre-hijo durante las primeras cinco semanas de vida infantil con la especie $M$. fuscata no se detectaron diferencias en los presupuestos de actividad materna, contacto físico madre-hijo, abrazo de la cría, tiempo total de amamantamiento y transporte del infante entre madres de hijos sin malformaciones congénitas en las extremidades, madres con hijos con malformaciones congénitas moderadas en las extremidades y madres con hijos con malformaciones congénitas severas en las extremidades. Las madres de infantes con malformaciones graves los sostenían manualmente durante la lactancia y locomoción significativamente más tiempo que otras madres. El aumento de la carga de apoyo y la lactancia de apoyo, así como la mayor frecuencia de sostener al infante contra el ventrum, sugieren que las madres de hijos con malformaciones congénitas extensas en las extremidades pueden estar invirtiendo más para facilitar la supervivencia de sus hijos y que la discapacidad infantil parece estar influyendo en los comportamientos maternos en esta población (Turner et al., 2005).

En 2008, Turner y colaboradores reportaron que la población de macacos japoneses aprovisionados en libertad del Awajishima Monkey Center ha incluido individuos con malformaciones congénitas en las extremidades durante al menos 40 años. De 1969 a 2007 un 16,1\% de las crías (185 de 1150) nacieron con malformaciones congénitas en las extremidades. Hay muchas etiologías posibles para las malformaciones congénitas en las extremidades y sus causas no se han establecido completamente, aunque algunos estudios han implicado ciertos plaguicidas organoclorados (Ito et al., 1988; Minezawa et al., 1990; citados por Turner et al., 2008). Se sabe relativamente poco sobre la demografía de las malformaciones congénitas 
en las extremidades en la población, particularmente las relaciones entre la ocurrencia y severidad de las malformaciones congénitas en las extremidades y la demografía por edad y sexo después de la infancia. Un censo en 2004 arrojó que, de un total de 199 monos, el 17,1\%, tenían malformaciones congénitas en las extremidades. Los autores crearon un índice que clasifica a los individuos en una escala de 0 a 1 según las extremidades y dedos afectados y ausentes, para estimar la gravedad de las malformaciones congénitas en las extremidades. La gravedad de estas varió mucho (rango de índice =0,01-0,79, media =0,29), con una variación similar en la gravedad en cada clase de edad y sexo (prueba t de Student, P 0,05). De acuerdo con los autores, la prevalencia de malformaciones congénitas en las extremidades en esta población es extremadamente alta, dado que este tipo de malformaciones normalmente son raras entre primates humanos y no humanos, con tasas de natalidad de malformaciones congénitas en las extremidades esperadas menores al 1\% (Froster-Iskenius y Baird, 1989; Brignolo et al., 2002; citados por Turner et al., 2008).

En 2012, Turner y colaboradores reportaron los datos de comportamiento de 11 hembras adultas con discapacidad y 12 controles sin discapacidad de M. fuscata de Awajishima. Cuantificaron diferencias de comportamiento estadísticamente significativas, todas relacionadas con la discapacidad entre hembras. Las hembras con discapacidad dedicaban menos tiempo a pedir cacahuates a los turistas y empleaban una variante conductual de la mendicidad de cacahuates; tenían menor frecuencia de uso de las manos para el aseo que compensaban con un mayor uso directo de la boca o una técnica de pellizco con dos brazos; también tenían una frecuencia más alta de rascarse a sí mismas y un mayor uso de los pies para esta conducta. Rascarse contra sustratos era casi exclusivamente un comportamiento asociado a la discapacidad. Dos hembras utilizaron el bipedalismo habitual. A pesar de estas diferencias, las hembras con discapacidad se comportaron de manera similar a los controles en muchos aspectos: la dependencia general de alimentos provistos y silvestres, el tiempo dedicado a la alimentación y la eficiencia de la alimentación no difirieron entre hembras, y no hubo diferencia de tiempo en el comportamiento realizado de manera arbórea o terrestre. Las hembras adultas con discapacidad pudieron compensar su comportamiento para realizar actividades sociales y de soporte vital, modificando los comportamientos existentes para adaptarlos a sus situaciones físicas individuales y, ocasionalmente, inventando nuevas formas de hacer las cosas (Turner et al. 2012).

En 2014, Turner y colaboradores publicaron un estudio sobre las consecuencias sociales de la discapacidad en primates no humanos, con base en sus observaciones de M. fuscata en Awajishima. Turner et al. (2014) recolectaron datos de comportamiento en 23 hembras adultas con y sin discapacidad durante tres temporadas consecutivas de parto. Sus resultados arrojaron que las hembras con discapacidad eran menos sociales en general en comparación con los controles sin discapacidad. Se describió que las hembras con discapacidad descansaron significativamente más y socializaron significativamente menos en comparación con los controles, y tenían menos hembras adultas afiliadas, menos hembras adultas como compañeras de aseo y dedicaban menos tiempo al aseo con otras hembras adultas. Algunas medidas sugirieron que las diferencias sociales eran el resultado de la flexibilidad de comportamiento por parte de las hembras con discapacidad que compensaban sus limitaciones con niveles más bajos de participación social y más descanso. Las hembras con discapacidad tuvieron tanto éxito en las solicitudes de cortejo como las hembras sin discapacidad y la proporción de afiliados con y sin discapacidad fue similar entre animales focales. Las hembras con discapacidad también fueron mordidas y perseguidas con menos frecuencia. En general, hubo poca evidencia para cuidados conespecíficos o por selección social frente a la discapacidad, así como una respuesta socialmente neutra a la discapacidad. Los autores plantean que, aunque el contexto social neutral permite la posibilidad de comportamientos de cuidado, sus hallazgos enfatizan las habilidades de autosuficiencia de estos primates con discapacidad y sugieren precaución al inferir cuidados conespecíficos, como han propuesto otros autores (Turner et al. 2014). 
Fedigan (1982, citada por Turner et al., 2018) planteó que el dominio social no es solo un reflejo del tamaño físico, la fuerza y la agresión en primates no humanos, sino que involucra una multitud de factores complejos y dinámicas sociales. Turner et al. (2018) examinaron los rangos de dominancia en relación con la discapacidad física en la población de $M$. fuscata de Awajishima, con base en datos de comportamiento en 38 hembras adultas, 12 con malformaciones congénitas en las extremidades, y en 22 machos adultos, 7 con malformaciones congénitas en las extremidades. Las hembras con discapacidad tendían a tener rangos de dominancia algo más bajos de lo esperado. Los machos con discapacidad se intercalaron en el orden de rango, sin una asociación significativa de la discapacidad con el rango de dominio, sin embargo, la clase de edad tuvo un efecto estadísticamente significativo en sus rangos de dominancia, ya que los machos mayores tendían a tener rangos más altos que los machos más jóvenes. Los resultados concordaron con Fedigan (1982, citada por Turner et al., 2018), demostrando algunas complejidades de las relaciones de dominancia en el contexto de la amplia variación física en este grupo de macacos.

En el más reciente trabajo publicado de este grupo, Espitia et al. (2020) reportaron sus observaciones sobre la influencia de la discapacidad en la eficiencia del aseo social en la población de M. fuscata de Awajishima. Las autoras plantean que los animales nacidos con discapacidades físicas pueden requerir, particularmente, flexibilidad e innovación en el comportamiento para sobrevivir y realizar actividades sociales, tal es el caso del aseo. Los estudios sobre macacos japoneses en libertad en la isla de Awaji, Japón, han demostrado que los individuos con malformaciones congénitas de las extremidades exhibieron comportamientos compensatorios durante el aseo, como un mayor uso de la boca y el codo para eliminar ectoparásitos. Su hipótesis fue que las técnicas modificadas de aseo utilizadas por los monos con discapacidad cumplían las funciones sociales y relajantes del acicalamiento, sin embargo, el aseo por individuos con discapacidades manuales aún puede conllevar un costo higiénico para los receptores. Las autoras encontraron que los monos con discapacidad manual eran acicaladores menos eficientes, pero sin diferencias significativas asociadas con el número de movimientos de acicalamiento por muestra entre los animales focales. Sus resultados también indican que la innovación y modificación de los tipos de movimiento no compensa por completo la discapacidad manual, la cual conlleva un costo para la función higiénica del aseo. Sin embargo, para el receptor del acicalamiento, la experiencia de ser aseado por un individuo con o sin discapacidad es probablemente similar y, a través de la compensación de movimientos, los monos con discapacidad pueden hacerlo y participar en el aspecto social del aseo sin incurrir en costos asociados con la discapacidad.

En otros estudios en M. fuscata, Nakai (2003) identificó los trastornos en huesos y articulaciones de individuos en vida libre para discernir algunos aspectos de su historia de vida. Los especímenes comprendieron 107 esqueletos casi completos de subadultos y adultos que fueron eliminados por ser monos asaltantes de cultivos entre 1997 y 1998 en la prefectura de Nagano, Japón. El trastorno más frecuente fue la deformidad angular debida a fracturas: 80 fracturas curadas en 31 de 52 machos y 71 fracturas curadas en 26 de 55 hembras. La osteoartritis secundaria por fracturas fue rara y solo hubo dos machos con osteocondritis disecante bilateral en la superficie posterior de los cóndilos femorales laterales. Los cambios degenerativos fueron comunes en los individuos mayores. Las fracturas del tronco (clavícula, escápula, vértebras, costillas o cadera) fueron frecuentes en los machos, mientras que en la mayoría de las hembras las fracturas estaban en manos y pies. La mayoría de las fracturas en los machos parecen haber ocurrido durante la edad adulta, y las de las hembras durante la niñez y la senescencia. La violencia interindividual no debe considerarse una causa principal de fracturas en machos y hembras porque no hubo ninguna herida por mordedura, excepto quizás en un caso de un dedo amputado. Las fracturas del tronco en los machos probablemente fueron causadas por fuerzas de impacto contra sus hombros o caderas, o ambos, al rodar por una pendiente pronunciada o caer de los árboles, tal vez durante las transferencias entre grupos. 
Por otro lado, Ogihara et al. (2005) realizó un análisis cinemático de la locomoción bípeda adquirida espontáneamente de un macho adulto de $M$. fuscata con malformaciones congénitas en las extremidades. Los autores midieron y compararon la locomoción bípeda de este individuo con dos monos altamente entrenados en este tipo de locomoción para evaluar la capacidad natural de un primate cuadrúpedo para este modo de caminar. El mono con malformaciones congénitas en las extremidades adquirió el bipedalismo por sí mismo debido a su carencia de antebrazos y manos. Los resultados mostraron que en el mono no entrenado todas las articulaciones estaban relativamente más flexionadas. Además, observaron el tobillo plantarmente menos flexionado y la rodilla más flexionada en la fase de apoyo media o tardía en el mono desentrenado, lo que sugiere que el tronco no se eleva hasta almacenar energía potencial. En los monos entrenados, las articulaciones se extienden para llevar el tronco lo más alto posible en la fase de apoyo, y luego la energía potencial almacenada se intercambia por energía cinética para avanzar. El eficiente mecanismo de péndulo invertido parece estar ausente en la locomoción del mono no entrenado, lo que implica que la adquisición de una locomoción bípeda tan eficiente no es una habilidad espontánea para un mono japonés. Más bien, es probable que sea una habilidad especial que solo se puede adquirir a través del entrenamiento artificial para un primate intrínsecamente cuadrúpedo (Ogihara et al., 2005). No obstante, la cabeza femoral izquierda del sujeto con malformaciones congénitas en las extremidades estaba deformada y dislocada, a diferencia del fémur derecho que parecía perfectamente articulado con el acetábulo, lo que sugiere que la articulación de la cadera izquierda de este sujeto se lesionó de alguna manera y el movimiento de la articulación había sido obstaculizado debido a una curación imperfecta (Ogihara et al. 2005).

\subsection{Estudios con chimpancés en vida libre}

De acuerdo con Quiatt et al. (2002, citados por Stokes y Byrne, 2006) se han registrado lesiones permanentes en chimpancés como resultado de trampas en todo su rango geográfico, las cuales, al menos en Uganda, son ilegales (Munn, 2003). Las trampas son colocadas por humanos vecinos del hábitat de la especie para atrapar otros mamíferos y consumirlos a nivel doméstico (Stokes y Byrne, 2001). Las lesiones llegan a generar la pérdida de manos, pies o la parálisis parcial o completa de al menos una extremidad (Waller y Reynolds, 2001; citados por Stokes y Byrne, 2006).

En 2001, Stokes y Byrne reportaron su estudio sobre el efecto de las trampas en chimpancés silvestres de Budongo, Uganda. La comunidad de estudio presentó más del $20 \%$ de sus integrantes con algún tipo de lesión en las extremidades superiores o inferiores como resultado de trampas. Desde una perspectiva cognitiva, los autores analizaron el procesamiento manual complejo de alimentos (hojas del árbol Broussonettia papyrifera) y la flexibilidad conductual en Pan troglodytes. De acuerdo con Stokes y Byrne (2001) los individuos capacitados utilizaron 15 técnicas (con preferencia por dos de ellas) de múltiples etapas cada una y que requerían diferenciación de roles bimanuales, en varias etapas y jerárquicas en su organización. Los autores hallaron que solo los chimpancés más gravemente lesionados mostraron una reducida eficiencia en su alimentación. Los individuos lesionados "solucionaron" sus discapacidades sin desarrollar técnicas totalmente novedosas y óptimas para sus lesiones específicas, más bien con cambios en la preferencia por técnicas particulares del repertorio general de la población. Dado que las lesiones por trampa generalmente afectan a los animales jóvenes, los resultados sugieren que los chimpancés aprenden técnicas en parte a través del aprendizaje observacional de individuos sanos (Stokes y Byrne, 2001).

En 2002, Byrne y Stokes reportaron un estudio de las habilidades de alimentación de un gorila y dos chimpancés que presentaban amputaciones y/o deformaciones en las manos. Dado que los gorilas también 
sufren heridas debido a las trampas de los cazadores, se ha estimado que entre el 10 y el $20 \%$ de los individuos de poblaciones de gorilas y chimpancés tienen lesiones graves en las manos (Byrne y Stokes, 2002). Los sujetos con discapacidad solo tuvieron ligeros compromisos en su eficiencia alimenticia y durante el tiempo de observación ninguno de los tres adquirió técnicas novedosas específicas para su capacidad restante, inclusive utilizaron técnicas similares a las de individuos sanos. Adaptaron las técnicas a sus limitaciones mediante la sustitución flexible de una gama de medios alternativos para lograr cada paso del proceso, incluidos agarres inusuales, uso de una mano en lugar de dos o viceversa, y uso de la boca o el pie. La compensación estaba en el nivel de ejecución detallada más que en la técnica general, y dependía de la transferencia de la organización motora a nuevos órganos efectores. Sus hallazgos tienen implicaciones para las teorías de la adquisición de habilidades manuales complejas y la caracterización de la flexibilidad de las habilidades mentales en los grandes simios (Byrne y Stokes, 2002).

En 2006, Stokes y Byrne reportaron adaptaciones de comportamiento e implicaciones a largo plazo en el comportamiento de alimentación como efecto de lesiones por trampas, en los chimpancés de Budongo. La capacidad de un individuo para superar sus lesiones es primordial para su supervivencia, y el hecho de que una proporción tan grande de la comunidad de Soso $(20 \%)$ haya sufrido y sobrevivido a un traumatismo importante en las extremidades sugiere que estos individuos pueden compensar sus lesiones a través de otras habilidades. El trabajo de Stokes y Byrne (2006) detalla preferencias de alimentos, posiciones en los árboles, posturas y técnicas de alimentación comparando individuos lesionados y no lesionados, reportando, por ejemplo, que los individuos lesionados de las manos usan sus pies para procesar el alimento, cosa que los sujetos sanos no hacen, sin encontrar efectos significativos de las lesiones en los tiempos de procesamiento de frutos de dos especies de Ficus Spp.

En su tesis de maestría, Munn (2003) describe las lesiones provocadas por trampas y que afectan el comportamiento social (especialmente el dependiente de la madre) y la locomoción de hembras adultas de chimpancés en la comunidad de Sonso, en Budongo. La autora reportó que nueve de los 49 miembros de la comunidad tenían lesiones graves por trampas, que iban desde dedos torcidos y destrozados a extremidades perdidas. Sus hallazgos identifican el efecto que tienen estas deformidades en cuatro parámetros conductuales principales: 1) estructura del grupo y patrones de asociación, 2) relaciones madre-hijo, 3) comportamiento de aseo, y 4) locomoción. Para lo anterior se observó durante ocho meses a 12 de las hembras adultas de las cuales cinco presentaban extremidades deformadas. Aunque los sujetos lesionados han sobrevivido a sus heridas, la autora detectó efectos conductuales como resultado de esas lesiones. Las hembras lesionadas, en comparación con las no lesionadas, se encontraron con mayor frecuencia en grupos pequeños, incluido el tiempo a solas con sus dependientes. Ellas también pasaron más tiempo en el espacio arbóreo. Las madres lesionadas brindaron menos apoyo que las no lesionadas a sus dependientes, esto hasta que alcanzaron una edad en la que pudieron alimentarse y viajar de forma independiente. Las madres lesionadas y no lesionadas atendieron a chimpancés jóvenes por igual. Los individuos con lesiones más extremas pasaron menos tiempo viajando que los menos heridos o no heridos, lo que sugiere que los animales gravemente heridos se ven más afectados por sus lesiones. Los chimpancés lesionados dedicaron menos tiempo a acicalar a otros, pero otros los acicalaron por igual en comparación con los individuos no lesionados. Los sujetos lesionados eran bien tolerados en la comunidad, y en particular las hembras lesionadas tenían la misma probabilidad de asociarse con otras hembras heridas o no lesionadas. Las hembras lesionadas pasaron más tiempo solas, con posibles consecuencias sociales a largo plazo, como una tasa de reproducción más baja o un mayor riesgo de mortalidad, lo cual puede afectar el crecimiento de la población en general (no dejar de considerar que se trata de una especie en peligro de extinción) (Munn, 2003). Esta 
misma autora publicó un estudio sobre los efectos de las trampas, específicamente en la locomoción de chimpancés en Budongo, considerando que esta especie se desplaza tanto en el suelo como en los árboles (Munn 2006). Informes del Parque Nacional Kibale, Uganda, describen a una hembra de chimpancé sin la mano derecha como una "temeraria increíble", quien, a pesar de su lesión, parecía una excelente escaladora y acróbata, aunque no mencionan su comportamiento antes de la lesión (Ghiglieri, 1988, citado por Munn, 2006). De acuerdo con Goodall (1968b, citada por Munn, 2003), en el Parque Nacional de Gombe, Tanzania, seis individuos con parálisis de las extremidades (casi con certeza por poliomielitis) se adaptaban bien a sus lesiones. Los resultados de Munn (2006) muestran que los chimpancés lesionados de la comunidad de Sonso utilizaron formas modificadas de los patrones locomotores típicos de los chimpancés no lesionados, así como una tendencia a evitar por completo algunos patrones locomotores. En algunos individuos el uso de formas modificadas de locomoción afectó el equilibrio necesario para los viajes arbóreos, así como la velocidad a la que viajaban, en especial cuando intentaban moverse rápidamente en el suelo. En general, las hembras lesionadas mostraban más incomodidad en su locomoción en comparación con los individuos sin discapacidad. El carácter de cada lesión determinó el tipo de locomoción adoptada, y el número de lesiones también afectó el nivel de discapacidad locomotora. Estudios anteriores han informado de que los chimpancés lesionados pueden moverse adecuadamente (Ghiglieri, 1988; Goodall, 1968; Kano, 1984; citados por Munn, 2006), por lo que un observador casual podría concluir que los chimpancés que sobreviven a sus heridas y a cualquier infección posterior pueden aprender a afrontar adecuadamente su discapacidad. Sin embargo, Munn (2006) pudo observar a dos hembras con las lesiones más graves perder el equilibrio o luchar con su balanceo en los árboles, lo que es potencialmente fatal. La muerte debida al efecto de este tipo de lesiones podría tener graves repercusiones para su descendencia dependiente y su comunidad (Munn, 2006).

Cibot et al. (2016) cuantificaron los hábitos de alimentación arbórea y las posturas de chimpancés adultos en libertad en Sebitoli, Parque Nacional de Kibale, Uganda. Los autores reportaron que, de 51 individuos, 16 de ellos $(31 \%)$ presentaron diversas anomalías en sus extremidades con diferente gravedad. Los chimpancés afectados treparon a los mismos árboles y tan alto como los chimpancés sin lesiones. Los chimpancés con discapacidad severa de la mano invirtieron mucho más tiempo en la alimentación que los individuos sin lesiones, y no se suspendieron de las ramas durante la alimentación con tanta frecuencia como los adultos sin lesiones. Asimismo, estos individuos utilizaron sustratos más grandes para agarrarse y sentarse que los adultos sin discapacidad, compensando de esta forma la realización de actividades de alimentación en los árboles (Cibot et al. 2016).

Amati et al. (2008) reportaron haber observado en la Estación Forestal de Conservación de Budongo, a un macho chimpancé ayudar a una hembra a quitarse una trampa de una mano. El macho rompió el pequeño árbol donde estaba colocada la trampa para que la hembra pudiera moverse de nuevo, sin embargo, la trampa todavía estaba alrededor de su mano, unida a un palo pequeño. Esta fue la primera vez que observaron a un chimpancé quitando una trampa a otro individuo. Para los investigadores resultó relevante la inspección minuciosa y cuidadosa eliminación de la trampa por parte de macho, que no solo quitó la trampa, sino que mantuvo el brazo de la hembra lesionada en posición para que no se lastimara más. A los autores no les resultó claro si el comportamiento del macho fue provocado por una mejora del estímulo ad-hoc (o cualquier otro proceso de aprendizaje social de bajo nivel) o comprendió el motivo del problema. En una comunidad donde muchos chimpancés tienen experiencia propia con trampas, parece posible que los individuos puedan establecer la conexión entre la trampa y los gritos involucrados, por lo que la experiencia puede permitirles quitar una trampa (Amati et al. 2008). Por su parte, Ohashi y Matsuzawa (2011) reportaron la desactivación de 
trampas por parte de chimpancés en Bossou, Guinea, donde sus comunidades y las aldeas humanas viven muy cercanas y existe una práctica generalizada de la caza con trampas en el área. Los resultados del estudio (222 días de observación) arrojaron seis intentos de desactivación de trampas, con dos intentos exitosos. Las observaciones indican que algunos chimpancés de Bossou reconocen las trampas como objetos peligrosos y pueden desactivarlas de forma segura y con ello evitar lesiones. Además, los chimpancés parecen saber qué partes de la trampa son peligrosas y cuáles no, pues en todos los casos observados tocaron o agarraron el palo arqueado de las trampas, evitando por completo el alambre enrollado. Si bien estos casos sugieren que los chimpancés son capaces de interactuar con seguridad e incluso desactivar las trampas, el riesgo de lesiones sigue siendo una posibilidad clara en Bossou (Ohashi y Matsuzawa, 2011).

Hobaiter y Byrn (2010) reportaron su estudio sobre un macho adulto con parálisis casi total de ambas manos debida a lesiones por trampas, en Sonso, Budongo. Este individuo compensaba su incapacidad de rascarse la espalda manualmente empleando una técnica distintiva de mantener tensa una liana en crecimiento mientras hacía movimientos corporales de lado a lado contra ella. Los autores observaron que siete jóvenes chimpancés sanos también usaban esta técnica de "rascado de lianas", aunque no tenían necesidad de hacerlo. La distribución de la técnica "rascado de lianas" se asoció estadísticamente con la superposición del rango de los individuos con el macho con discapacidad y la cantidad de tiempo que pasaron en grupo con él, confirmando que la técnica se adquiere mediante aprendizaje social. Los autores desconocen la motivación de los chimpancés sanos para copiar esta variante, pero el hecho de que lo hagan es una prueba de que el aprendizaje imitativo de los procedimientos motores de otros es un rasgo natural de los chimpancés salvajes (Hobaiter y Byrn, 2010).

Matsumoto et al. (2016) han reportado el desarrollo físico y conductual de una cría de chimpancé con posible retraso en su desarrollo neurológico, el cual fue inferido por sus expresiones faciales, inactividad general e incapacidad para sentarse antes de los 20 meses, siendo este caso similar al de un individuo de chimpancé cautivo con síndrome de Down (McClure et al. 1969, 1973; citados por Matsumoto et al. 2016). Aunque las discapacidades congénitas se han documentado en diversos grupos de primates, hay pocos casos estudiados sobre las interacciones entre una hembra y una cría con anomalías severas (Matsumoto et al. 2016). Estos autores plantean que la madre de una cría con discapacidad grave probablemente experimenta más estrés que otras madres debido a los cuidados intensivos y durante más tiempo, como ya se pudo observar en un caso en cautiverio (Kumazaki et al. 2010; citados por Matsumoto et al. 2016). En el caso reportado por Matsumoto et al. (2016) el cuidado temporal otorgado a la cría por una hermana mayor (de 10-11 años, aproximadamente) contribuyó a aliviar el estrés de la madre en cierta medida, por ejemplo, para poder alimentarse, y es posible que la finalización del cuidado de la hermana, cuando ella tuvo a su propia cría, nuevamente haya aumentado la carga de cuidado de la madre (Matsumoto et al. 2016). Las observaciones de esta madre chimpancé y su cría con discapacidad congénita grave contribuyen a adquirir conocimientos sobre la atención durante la infancia, período en el que la atención materna es más necesaria (Nakamichi et al. 1983; Turner et al. 2005; citados por Matsumoto et al. 2016). En este caso de la cría chimpancé con trisomía, los autores observaron un cuidado familiar por parentesco (la hermana), comentando que no pueden concluir que el cuidado no parental esté totalmente ausente en los chimpancés, ${ }^{3}$ como proponen algunos autores (Struhsaker et al. 2014; citados por Matsumoto et al. 2016).

3. En un documental, la primatóloga Jill D. Pruetz explica el comportamiento altruista de un chimpancé macho juvenil con la cría de meses de edad de una hembra lesionada que no podía cuidar a su hija. El joven chimpancé no tenía parentesco con las hembras que ayudó. "Chimps, nearly humans", by Eleanor Grant (2009), National Geographic Inc. En: https://www.youtube.com/watch?v=4YObdu_qBF4 (minutos: 6:32 a 10:18). 


\subsection{Estudios con chimpancés en cautiverio}

Russell (2010) analizó el acicalamiento social entre chimpancés cautivos en el zoológico de Chester, Reino Unido. El autor eligió siete sujetos para estudiar la dinámica social de terceros: las decisiones de acicalamiento de cinco machos adultos en la medida en que dirigían su atención a una pareja madre-hija. La hija era una subadulta impopular y físicamente con discapacidades motoras congénitas que le impedían acicalar a los demás de manera efectiva. Russell (2010) observó que algunos machos aumentaron su acicalamiento hacia la hija con discapacidad durante los días en que la madre tenía una hinchazón anogenital tumescente (sexualmente atractiva para los machos) en comparación con los días en que la madre no era tumescente (menos atractiva). Aparentemente, los machos estaban acicalando a la hija sin posibilidad de retribución (porque la hija nunca pudo «devolverles el favor»). Se calculó una «tasa de aseo» (tiempo medio de aseo/hora) que mostraba los esfuerzos de aseo de los cinco machos hacia la madre y la hija. Estas tasas se compararon en los días en que (1) la hinchazón anogenital de la madre era tumescente y (2) los días en que la hinchazón no era tumescente. Cada macho mostró un patrón de comportamiento diferente. Dos machos acicalaron a la hija significativamente más cuando la madre estaba tumescente. Los resultados de todos los machos se compararon con la calidad de la relación social entre cada macho y la madre. Aparentemente, solo los machos que tenían una relación más débil con la madre acicalaban más a la hija cuando la madre estaba tumescente. Este patrón no existía para los machos con una relación más fuerte con la madre. Posiblemente, los machos inseguros estaban utilizando a la hija con discapacidad como una forma de ganarse el favor de la madre atractiva. Si esto se confirma, entonces este tipo de situación triádica es un escenario posible para que ocurra la reciprocidad indirecta.

Por su parte, Ang et al. (2016) evaluaron los comportamientos, desplazamiento y uso del espacio de una hembra en un zoológico, antes y después de la amputación quirúrgica de su miembro anterior derecho. Estos autores determinaron que en general la lesión no afectó sustancialmente las actividades diarias de esta hembra ya que no mostró ningún cambio en su uso del espacio vertical, pasando proporciones equivalentes de su tiempo en el suelo y en lo alto del recinto. Los autores proponen que este estudio de caso proporciona evidencia de los ajustes exitosos a cambios anatómicos significativos en los individuos de esta especie cuando se les proporciona un entorno adecuado para mantenerse activos (Ang et al., 2016).

Finalmente, para la especie Pan troglodytes, Hirata et al. (2017) reportan el caso de una hembra en cautiverio con trisomía 22 (mutación genética similar a la trisomía 21 humana). Esta hembra identificada con el nombre de Kanako, fue rechazada por su madre a los dos meses de nacida, situación que sucedió cuando los investigadores las separaron para hacer una revisión médica a la madre, quien estando anestesiada se mordió la lengua, por lo que la tuvieron en observación varios días. Al intentar reunirla con su cría la rechazó, entonces los investigadores se hicieron cargo de Kanako, quien a causa de la trisomía fue perdiendo la vista progresivamente hasta quedar ciega a los siete años. Para cuando Kanako tenía 18 años, los investigadores la pusieron en contacto con Román, otra hembra de chimpancé nacida en libertad, para que pudiera tener contacto social conespecífico. Román fue amistosa con Kanako desde el comienzo, y de vez en cuando trataba de acicalarla o la invitaba a jugar, pero su interacción en general no duraba mucho porque Kanako no se movía ni reaccionaba, o se alejaba. En algunas ocasiones, Kanako se acercó a Román, quien la tocó suavemente, pero esto solo sucedió en raras ocasiones ya que, por lo general, simplemente se sentaban una cerca de la otra y pasaban el tiempo en silencio. Al comienzo de las sesiones de encuentro, Kanako casi siempre emitía una vocalización específica para ella, que era una mezcla de gruñido de chimpancé y gruñido de comida, lo que indicaba su reacción positiva hacia la sesión de encuentro (Hirata et al. 2017). 


\subsection{Estudios en bonobos}

Kano (1984) reportó sus observaciones de anomalías físicas entre los bonobos silvestres de Wamba, Zaire. De 96 animales en una muestra que abarcó todas las clases de edad y sexo de dos grupos naturales diferentes, 46 individuos tenían al menos un defecto en las extremidades. La frecuencia de anomalías fue mayor en machos que en hembras y aumentó directamente con la edad. Casi todas las crías y jóvenes tenían extremidades completamente normales, pero prácticamente todos los machos y más de la mitad de las hembras que habían alcanzado la madurez tenían uno o más defectos en las extremidades. De acuerdo con este autor, los hallazgos indican que los factores congénitos contribuyen poco a la frecuencia de anomalías en esta muestra. La tasa de supervivencia fue la misma en individuos con defectos que en aquellos sin defectos, y el estatus social individual parecía ser mucho más importante en la obtención de alimentos que la capacidad locomotora. La condición más grave de anomalías fue en las extremidades, las cuales ejercen una influencia obvia en la locomoción. Se observó un individuo con ambas piernas rígidas y cuya única forma de locomoción en el suelo era "con muletas" (Goodall, 1968; citada por Kano, 1984), es decir, impulsando el cuerpo hacia adelante con el fulcro, alternando entre las dos manos juntas y las dos piernas juntas. En los árboles, este sujeto se movía horizontalmente "con muletas", combinado ocasionalmente con balanceo de brazos, mientras que sus movimientos verticales los lograba casi completamente solo con las manos. Sus movimientos eran siempre muy lentos, pero fue capaz de trepar a la copa de los árboles más altos para alimentarse. Kano (1984) concluye que, en estos bonobos, las anormalidades observadas como factor selectivo en la competencia intraespecífica se minimizaba en la red de sus relaciones sociales.

Tokuyama (2019) reportó un bonobo macho adulto cuyas extremidades superiores estaban muy deformadas y exhibían los efectos típicos de las lesiones por trampa de lazo. Su extremidad superior izquierda se había deformado antes de ser identificado por primera vez en 2007. Su mano derecha quedó atrapada en una trampa en septiembre de 2009 y el cable de la trampa no se cayó hasta noviembre de 2010. El pulgar y las partes restantes de los cuatro dedos de su mano izquierda eran capaces de cierta cantidad de movimiento, aunque con torpeza. Su mano derecha y su muñeca estaban rígidas. Aunque era más lento que otros individuos, podía trepar a los árboles sujetándose de los troncos con ambos brazos. En 2017 este individuo volvió a quedar atrapado por la muñeca en una trampa. Uno de los asistentes humanos que lo descubrieron, al ver al bonobo exhausto, quebró el árbol donde estaba la trampa y el bonobo corrió. Días después el sujeto volvió a ser observado, presentando severas heridas abrasivas en el interior y el exterior de la muñeca izquierda, pero sin mostrar signos aparentes de debilidad. Después de sobrevivir a la infección inicial, se había considerado que las lesiones por la trampa tenían un efecto mínimo en la supervivencia de un individuo (Kano 1984; Stokes 1999; citados por Tokuyama, 2019). Sin embargo, este caso muestra que las lesiones por trampa pueden causar accidentes graves incluso años después de la lesión original. Por otra parte, los integrantes en el grupo del macho lesionado, si bien no intentaron ayudarlo, se acercaron mostrando curiosidad, el día del accidente lo dejaron solo durante la noche para ir a su sitio de pernoctación, pero regresaron al día siguiente al lado del macho atrapado en la trampa. El autor considera dos posibilidades de motivación para que los bonobos vuelvan a visitar a los heridos. Primero, preocupación por los sujetos lesionados o inmovilizados. Aunque los bonobos dejan a los individuos lesionados para alimentarse o encontrar lugares adecuados para dormir, es posible que regresen más tarde para verificar el estado de la víctima. La otra posibilidad es que los bonobos tienden a sentirse atraídos por eventos irregulares (Tokuyama, 2019). 


\subsection{Estudios en gorilas}

Se encontró un solo trabajo por Byrne y Stokes (2002) ya comentado en la sección sobre chimpancés.

\subsection{Estudios en babuinos}

Struhsaker et al. (2010) describieron y documentaron con imágenes digitales a una hembra adulta de babuino (Papio anubis) del Parque Nacional Kibale, Uganda, sin premaxilar y muy poco del maxilar y la nariz, por causas muy probablemente congénitas, dada la simetría de la deformidad y la falta de tejido cicatricial. A pesar de la gravedad del caso, la hembra parecía sana, bien integrada social y aparentemente reproduciéndose, basándose en el hecho de que parecía estar preñada y a que estaba acicalando y amamantando a una hembra juvenil. Su extrema deformidad plantea numerosas preguntas y demuestra las capacidades altamente adaptables de los babuinos salvajes (Struhsaker et al. (2010).

Por otra parte, Beamish y O'Riain (2014) reportaron los efectos de lesiones permanentes en el comportamiento y la dieta de babuinos chacma (Papio ursinus). En la Península del Cabo, Sudáfrica, los miembros de la población de babuinos chacma experimentan niveles crónicos de conflicto con los humanos que se manifiesta en niveles altos de babuinos con discapacidad (15\%) en grupos que se superponen con áreas residenciales. Los autores investigaron el impacto potencial de tales discapacidades comparando el comportamiento y la dieta de los babuinos con discapacidad con los babuinos ilesos emparejados estrechamente por edad, sexo y estatus social de grupos de un tamaño y composición similares, durante ocho meses. Los babuinos con discapacidad pasaban más tiempo descansando y viajando, mientras que ocuparon menos tiempo alimentándose que los babuinos ilesos. Los babuinos con discapacidad e ilesos tenían dietas similares, pero los primeros consumían menos alimentos con altos costos de manipulación y se alimentaban más con alimentos antropogénicos de alto rendimiento que los segundos. No hubo diferencia en la frecuencia de los comportamientos de aseo o vigilancia social, como podría esperarse si la discapacidad hubiera comprometido la capacidad competitiva o el riesgo de depredación. Además, no hubo diferencia en la supervivencia de los individuos con discapacidad o ilesos en cada grupo. Los resultados sugieren que, si bien las lesiones permanentes pueden afectar el comportamiento y la dieta de estos babuinos, las limitaciones pueden compensarse con el acceso a fuentes de alimentos antropogénicas y la falta de depredadores naturales. La discapacidad en los babuinos puede llevar a un asalto obligado de alimentos antropogénicos de alto rendimiento, lo que es un desafío importante para el manejo continuo de esta población (Beamish y O’Riain, 2014).

\subsection{Estudios en macacos toque}

Dittus y Ratnayeke (1989) estudiaron las respuestas de comportamiento individual y social a lesiones en macacos salvajes (Macaca sinica). Los macacos que habitan el bosque natural en Polonnaruwa, Sri Lanka, son frecuentemente heridos en peleas entre conespecíficos. Los animales heridos descansaron y se alimentaron más, pero buscaron e iniciaron menos episodios agresivos. Pasaron la mayor parte del tiempo de forma sedentaria en sus refugios arbóreos y redujeron sus movimientos acrobáticos al desplazarse más a menudo por tierra. Otros miembros del grupo no mostraron tolerancia especial o altruismo hacia las víctimas de lesiones durante la actividad costosa y altamente competitiva de buscar comida. De hecho, algunos animales heridos recibieron más agresión o perdieron el rango de dominio y, por lo tanto, sus habilidades 
competitivas se vieron aún más afectadas. El cuidado de los heridos se manifestó principalmente mediante aseo y limpieza de heridas. Eliminaban todo el pelo en el área que rodeaba una herida, así como suciedad, costras y larvas de mosca, y aplicaban saliva lamiendo la herida. Las heridas así tratadas curaron sin signos evidentes de infección. Los autores concluyen que: 1) los macacos heridos buscaron y recibieron mayor acicalamiento de forma significativa (cuidado de las heridas); 2) la cantidad de cuidado recibido aumentó con la gravedad de la lesión; y 3) la iniciativa de otros miembros del grupo a menudo compensaba la incapacidad de la víctima para solicitar cuidado. Los machos jóvenes estaban especialmente atentos a los machos adultos heridos, lo que sugiere que estaban invirtiendo en un vínculo social con estos adultos. Las hembras jóvenes lesionadas recibieron la mayor parte de cuidado de sus madres (Dittus y Ratnayeke, 1989).

\subsection{Estudios en otras especies de monos africanos}

Existen otros reportes para especies de primates diferentes a las anteriormente señaladas, por ejemplo Arlet et al. (2009) compararon lesiones y deficiencias por especie, edad y sexo, en cuatro especies de primates: 13 grupos de colobo blanco y negro Colobus guereza, nueve grupos de colobo rojo Piliocolobus tephrosceles, seis grupos de monos de cola roja Cercopithecus ascanius y seis grupos de mangabeys de mejillas grises Lophocebus albigena) en el Parque Nacional Kibale (Uganda). Las especies difirieron en la proporción de individuos con lesiones y deficiencias, con $16,7 \%$ en C. guereza, 23,1 \% en P. tephrosceles, $16,2 \%$ en C. ascanius y $30,2 \%$ en $L$. albigena. Las especies también difirieron en los tipos y la ubicación en el cuerpo de las lesiones. Los animales adultos tenían más heridas que los inmaduros. Excepto en $C$. ascanius, en las tres especies restantes los machos tenían más lesiones que las hembras. Las posibles causas de deficiencias y lesiones son numerosas y pueden variar entre especies, sexos y entornos (por ejemplo, arbóreos frente a terrestres). Las causas rara vez se observan directamente y a menudo se especula sobre ellas según el tipo y la ubicación en el cuerpo de las lesiones (Crockett y Pope 1988, citados por Arlet et al. 2009). El tipo y la distribución en el cuerpo de las lesiones y deficiencias también pueden estar relacionados con la susceptibilidad a fracturas que se asocia con los tipos de locomoción, así como qué partes del cuerpo son el objetivo de los agresores (Schultz 1944; McGraw et al., 2006; citados por Arlet et al. (2009). Tanto los datos sobre lesiones en animales vivos como sobre esqueletos reflejan la incidencia de lesiones y la capacidad de sobrevivir a ellas (Bulstrode et al. 1986, citados por Arlet et al. 2009).

\subsection{Estudios en monos araña}

El único estudio sobre una especie de primate no humano del nuevo mundo corresponde a Chapman y Chapman (1987). Estos autores reportaron el desarrollo conductual de un mono araña macho juvenil (Ateles geoffroyi) antes y después de una lesión traumática que provocó la pérdida de la cola, observado por un período de nueve meses en el Parque Nacional Santa Rosa, Costa Rica. El sujeto se volvió muy dependiente de su madre, quien le brindó cuidados compensatorios, incluido el amamantamiento a pesar de que había sido destetado anteriormente. En comparación con otro mono araña macho juvenil de edad similar, el desarrollo del animal lesionado se retrasó severamente, cinco meses después del accidente el juvenil todavía era amamantado y llevado por su madre. Como las lesiones pueden ser relativamente comunes entre los primates, Chapman y Chapman (1987) sugieren que la provisión de cuidados compensatorios es un rasgo importante en muchas especies de primates. 


\subsection{Estudios en monos rhesus}

De acuerdo con Turner (1999) la investigación conductual existente sobre la discapacidad en primates no humanos se había centrado principalmente en las crías y en ocasiones había involucrado experimentos crueles en individuos sanos (Dicks et al., 1969; Lindburg, 1969; Berkson, 1974; citados por Turner, 1999). Derivado de un estudio teratológico, Lindburg (1969) estudió el comportamiento de dos monos rhesus lactantes con malformaciones (falta de miembros superiores) inducidas por el fármaco talidomida. En cautividad, estos infantes lograron "niveles adecuados" de interacción materna, con sus compañeros y con su entorno, desarrollando formas apropiadas para cada individuo de interactuar, caminar bípedos y usar la boca y pies para tareas que normalmente estarían orientadas a las manos (Lingburg, 1969).

\subsection{Estudios en gibones}

Sayer et al. (2007) reportaron las conductas locomotoras, posturales y manipuladoras de un gibón (Nomascus leucogenys) cautivo, juvenil y con un solo brazo, comparándolas con los perfiles de conducta de los miembros de su familia. Dado el predominio de la braquiación y otras formas de suspensión en la locomoción del gibón, los autores esperaban que el sujeto cuyo brazo fue amputado por una lesión intratable aproximadamente un año antes de iniciar las observaciones, evitara la locomoción suspendida, para pasar más tiempo inmóvil y tener menos probabilidades de exhibir posturas que implicasen suspensión de las extremidades anteriores. El sujeto focal y su hermano menor tenían niveles de actividad similares, y aunque existían diferencias en los perfiles posturales, eran sorprendentemente pocas. Específicamente, el sujeto amputado pasó significativamente menos tiempo en movimiento y en formas de locomoción no suspensivas que su hermano. En comparación con sus padres, el individuo sin un brazo estaba activo y en movimiento con más frecuencia, pero era menos probable que exhibiera la postura de suspensión de las extremidades anteriores. A pesar de las crecientes demandas energéticas asociadas con la braquiación con un solo brazo, este sujeto prefirió la locomoción en suspensión a otras formas de locomoción. Además, encontró soluciones únicas para buscar comida y moverse, a menudo haciendo uso de sus pies y dientes, y generalmente fue el primero en acercarse y manipular objetos de enriquecimiento. Los autores no encontraron evidencia que sugiera que la amputación del brazo hubiera alterado los niveles de actividad del sujeto focal. Aunque el gibón de un brazo mostró comportamientos locomotores, posturales y manipuladores ligeramente diferentes a los de los miembros de su familia, parecía bien adaptado a su lesión (Sayer et al. (2007).

\section{Discusión y conclusiones}

De acuerdo con Turner et al. (2014) sus hallazgos sobre la respuesta social neutra a individuos con discapacidad en la población de $M$. fuscata en Awajishima sugieren precaución al inferir cuidados conespecíficos entre primates no humanos hacia sujetos con discapacidad, incluso en humanos ancestrales con discapacidad grave, como plantean algunos autores (Trinkaus y Zimmerman, 1982; Lordkipanitze et al. 2005; citados por Turner et al. 2014). Sin embargo, el incremento de cuidados maternos a crías, infantes y juveniles con 
discapacidades congénitas o adquiridas observado en diferentes especies es frecuente y esencial para la supervivencia de esta descendencia, a costa de la posible inversión negativa de la madre para su propia supervivencia y nuevas reproducciones. En algunas especies se han observado cuidados conespecíficos a los individuos lesionados, como en Macaca sinica (Dittus y Ratnayeke; 1989) y en chimpancés (Amati et al. 2008). Aun se sabe poco sobre el tratamiento social positivo, neutral o negativo hacia individuos con discapacidades físicas en primates no humanos (Turner et al. 2014), por lo que el debate parece persistir. No obstante, y a pesar de la diversidad conductual entre especies de primates, entre grupos de una misma especie y entre individuos dentro de los grupos, los estudios revisados reflejan las siguientes tendencias generales:

- Mayor cuidado materno a crías, infantes y juveniles con malformaciones o lesiones, para compensar sus discapacidades.

- Los sujetos con malformaciones y lesiones compensan las deficiencias físicas mediante flexibilidad conductual, por ejemplo, agregando, omitiendo o remplazando pasos en determinadas técnicas alimenticias y en sus formas de locomoción.

- La discapacidad no necesariamente limita la reproducción, como muestran los registros de hembras con discapacidad con descendencia.

- En cuanto al aseo social, una conducta muy importante en los primates no humanos, se ha observado entre chimpancés que los sujetos con discapacidads reciben más aseo del que ellos mismos pueden otorgar (Munn, 2003) y entre macacos japoneses la socialización durante el aseo recíproco parece ser más importante que la eficiencia en la eliminación de suciedad y parásitos, por lo que los individuos con limitaciones físicas pueden participar de esta actividad con el resto de su grupo (Turner et al. 2014).

- Individuos adultos con discapacidades sobreviven sin cuidados de conespecíficos, es decir, son autosuficientes a pesar de sus limitaciones funcionales, y la tendencia al aislamiento social de algunos de estos individuos con discapacidad puede ser una posible estrategia compensatoria de sus deficiencias de locomoción y alimentación, y no el resultado del rechazo de los demás integrantes de sus grupos.

Las ideas de "la sobrevivencia del más apto" y "la lucha por la existencia" propuestas por Wallace (1858) y Darwin (1859) en sus respectivas versiones de la teoría de evolución por sección natural fueron tomadas para justificar los nuevos modelos colonizadores y económicos de la época con un importante apoyo ideológico (Gare, 2017). Posterior a estos autores, han surgido nuevas propuestas científicas, como la teoría sintética de la evolución o "neodarwinismo", que intentó reunir la selección natural con las leyes de la herencia fundamentada en los trabajos pioneros de Gregorio Mendel. Para Gare (2017) esta teoría presenta serios problemas de lógica: plantear que los genes más aptos sobreviven y pueden identificarse por haber sobrevivido, demostrando que estaban en mejores condiciones, es plantear una tautología (Gare, 2017). Diferentes investigadores han encontrado que ideas pre-darwinianas como la herencia de caracteres adquiridos de Lamarck podrían explicar fenómenos epigenéticos (Gare, 2017). Inclusive, Friedrich Schelling, filósofo idealista alemán, caracterizó a los organismos como entes autocreadores, que mantienen sus formas mientras interactúan con sus entornos, modificándolos para convertirlos en mundos posibles para sus fines (Schelling, [1799] 2004, citado por Gare, 2017). Estudios post-darwinistas se han centrado en la idea de que los organismos modifican sus entornos en lugar de solo ser seleccionados por estos: al aumentar sus entornos los organismos aumentan sus probabilidades de sobrevivir (Gare, 2017). Para Gare (2017) la apreciación de este hecho facilita entender la simbiosis y las formas en que ésta se desarrolla, pues la simbiosis es mucho más importante que la competencia entre individuos para la biodiversidad (Gare, 2017). 
Aunque el debate académico parece haber superado el discurso del darwinismo social, en la vida cotidiana las sociedades contemporáneas siguen sustentadas en la competencia, exaltando la individualidad ${ }^{4} \mathrm{y}$ recurriendo a la cooperación solo en función de objetivos de mayor nivel competitivo. En un sistema de producción y consumo de productos y servicios que se focaliza en obtener las mayores ganancias a los menores costos -la eficiencia del mercado- las personas con insuficiencias físicas y/o cognitivas podrían resultar falsamente como elementos inadecuados. Contradictoriamente, el sistema empresarial, que normalmente excluye a las personas con limitaciones productivas o de consumo, no duda en recurrir a ellas cuando puede sacarles provecho. Así, por ejemplo, en Inglaterra estudios oficiales indicaban que al menos siete de cada diez personas con discapacidad que estaban en edad de trabajar carecían de empleo (Martin et al., 1988; citados por Oliver, 1998). Sin embargo,

"Durante la Segunda Guerra Mundial, alrededor de 430.000 discapacitados que habían sido excluidos previamente del mercado de trabajo se incorporaron a las fábricas y a la industria, y no solo en labores de muy escasa relevancia, sino a menudo en puestos importantes de supervisión y gestión (Humphreys y Gordon, 1992). Me parece que la razón es muy sencilla. El objetivo del trabajo durante esas dos guerras no era obtener el máximo beneficio sino luchar contra el enemigo común. Se organizaba el trabajo según los principios de la cooperación y la colaboración, y no sobre los de la competición y la obtención del beneficio máximo” (Oliver, 1998, p. 50).

Si bien la competencia por recursos para la supervivencia y la reproducción es un factor de evolución, podría no ser el único y es posible que existan otros de igual importancia para perpetuar la especie. Inclusive, Darwin había observado la importancia de la cooperación y la solidaridad para la sobrevivencia en grupo. Este autor sugirió una posible vía evolutiva de la consciencia y la moral en animales con instintos gregarios, donde los afectos filiales como base de lo social serían instintivos y adquiridos por selección natural, pero susceptibles de fortalecer mediante el hábito (Darwin, ([1891] 1904). Algunas ideas de la teoría de la evolución por selección natural fueron tergiversadas por la ideología del darwinismo social, llevando a malentender el concepto de evolución biológica como "progreso", justificando de esa manera la política económica dominante de esos momentos y que se implementó a partir de la revolución industrial. Davis (2007) invita a reflexionar acerca de qué cosa, situación o evento es lo "normal" en los seres humanos:

"[¿Cuál es?] la razón por la que querríamos vivir en un mundo donde los signos de discapacidad, vulnerabilidad o diferencia corporal tienen que esconderse. Parece encajar con fenómenos parecidos: los viejos recluidos en asilos, los discapacitados en instituciones, los pobres en guetos. ¿Cómo es la vida de la gente "normal" cuando nunca tienen que confrontarse con personas que se ven y, de hecho, son diferentes? ¿Será posible comprender nuestra humanidad sin habernos encontrado con alguien diferente? [...] Los encuentros con la diferencia nos brindan la oportunidad de reflexionar sobre nosotros mismos y los demás, lo cual resulta esencial para nuestra humanidad. Sin eso, nuestras vidas pueden volverse menos dignas de ser vividas" (Davis, 2007, pp. 174-175).

En los casos de personas con severas limitaciones físicas, congénitas o adquiridas que han logrado integrarse a la vida laboral, deportiva y/o a otras dinámicas sociales, se observa una importante flexibilidad conductual de ellas y de sus familias para resolver problemas cotidianos, explorando y desarrollando sus propios recursos físicos y cognitivos. No obstante, generalmente, estas familias tienen que lidiar con diversas barreras: burocracia, médica, educativa y laboral, limitaciones económicas (Lee et al. 2018) y, sobre todo, con estigmas sociales que dificultan la vida cotidiana fuera de su ámbito doméstico y familiar. Res-

4. Resulta significativo que los nuevos productos de informática y telefonía móvil, con gran demanda a nivel global, se estén desarrollando principalmente para uso individual y se comenzaron a promocionar con nombres como personal computer (PC), Ipod, Iphone o Ipad. 
pecto al darwinismo social y su representación de un mundo que mejora con base en la competencia y la supervivencia solo de los más aptos, quizás nos falten elementos en los tiempos modernos para justificar la competencia e inequidad social. Aún tenemos mucho camino por recorrer, y sobre todo incorporar, para una mejor interpretación de los preceptos de la teoría evolutiva validando y revalorizando el papel de quienes no necesariamente se presentan como "los más aptos". 


\section{Referencias bibliográficas}

Aguado, A. L. (1995). Historia de las deficiencias. Escuela Libre Editorial, Fundación Once, Colección Tesis y Praxis.

Amati, S. et al. (2008). Snare removal by a chimpanzee of the Sonso community, Budongo Forest (Uganda). Pan Africa News, 15(1), pp. 6-8.

Ang, M. Y. L. et al. (2016). Assessment of behavior and space use before and after forelimb amputation in a zoohoused chimpanzee (Pan troglodytes). Zoo Biol, 36(1), pp 5-10.

Arlet, M. E. et al. (2009). Species, age and sex differences in type and frequencies of injuries and impairments among four arboreal primate species in Kibale National Park, Uganda. Primates, 50, pp. 65-73.

Beamish, E. K. y O'Riain, M. J. (2014). The Effects of Permanent Injury on the Behavior and Diet of Commensal Chacma Baboons (Papio ursinus) in the Cape Peninsula, South Africa. Int J Primatol. https://doi.org/10.1007/ s10764-014-9779-z.

Beltrán, O. A. (2005). Revisiones sistemáticas de la literatura. Rev. Colombiana de Gastroenterología, 20(1), pp. 60-69.

Byrne, R. W. y Stokes, E. J. (2002). Effects of Manual Disability on Feeding Skills in Gorillas and Chimpanzees. Int J Primatol, 23, pp. 539-554.

Chapman, C. A. y Chapman, L. J. (1987). Social Responses to the Traumatic Injury of a Juvenile Spider Monkey (Ateles geoffroyi). Primates, 28(2), pp. 271-275.

Cibot, M. et al. (2016). Feeding Consequences of Hand and Foot Disability in Wild Adult Chimpanzees (Pan troglodytes schweinfurthii). Int J Primatol, 37, pp. 479-494.

Conadis (2012). Encuesta Nacional sobre Discriminación en México / Enadis 2010 Resultados sobre personas con discapacidad. Consejo Nacional para el Desarrollo y la Inclusión de las Personas con Discapacidad.

Darwin, C. (1859). On the origin of species by means of natural selection, or the preservation of favoured races in the struggle for life, John Murray, Albemarle Street. https://ia803002.us.archive.org/0/items/onoriginofspecie1859darw/onoriginofspecie1859darw.pdf.

Darwin, C. ([1891] 1904). El origen del hombre. La selección natural y la sexual. F. Sempere Y Ca , Editores. https:// medicina.ufm.edu/images/7/7c/Elorigendelhombre_POR_CHARLES_DARWIN.pdf.

Davis, K. (2007). El cuerpo a la carta. Estudios culturales sobre cirugía cosmética. La Cifra Editorial.

Dittus, W. P. J. y Ratnayeke, S. M. (1989). Individual and Social Behavioral Responses to Injury in Wild Toque Macaques (Macaca sinica). Int J Primatol, 10(3), pp. 215-234.

Espitia, J. P. et al. (2020). Social grooming efficiency and techniques are influenced by manual impairment in freeranging Japanese macaques (Macaca fuscata). PLoS One, 15(2), p. e0228978.

Gare, A. (2017). Darwinism. En B. S. Turner et al. (Eds.), The Wiley-Blackwell Encyclopedia of Social Theory, 5 volumes. John Wiley \& Sons.

Hirata, S. et al. (2017). Chimpanzee Down syndrome: a case study of trisomy 22 in a captive chimpanzee. Primates, 58, pp. 267-273. 
Hobaiter, C. y Byrne, R. W. (2010). Able-Bodied Wild Chimpanzees Imitate a Motor Procedure Used by a Disabled Individual to Overcome Handicap. PLoS ONE, 5(8), p. e11959.

Kano, T. (1984). Observations of Physical Abnormalities Among the Wild Bonobos (Pan paniscus) of Wamba, Zaire. Am J of Phys Anthropol, 63, pp.1-11.

Lee, C. E. et al. (2018). Comparing differences in support needs as perceived by parents of adult offspring with down syndrome, autism spectrum disorder and cerebral palsy. J Appl Res Intellect Disabl, 32, pp. 194-25.

Lindburg, D. G. (1969). Behavior of infant rhesus monkeys with thalidomide-induced malformations: A pilot study. Psychon Sci, 15(1), pp. 55-56.

Matsumoto, T. et al. (2015). An observation of a severely disabled infant chimpanzee in the wild and her interactions with her mother. Primates, 57, pp. 3-7.

Milella, M. et al. (2015). A Neolithic Case of Mesomelic Dysplasia from Northern Switzerland. Int. J. Osteoarchaeol, 25, pp. 981-987.

Munn, J. (2003). The Impact of Injuries on Free-living Chimpanzees. How injury effects the social behaviour, motherdependant behaviour and the locomotion of adult fem ale chimpanzees from the Sonso community, Budongo Forest Reserve, Uganda [Tesis de Maestría, Australian National University].

Munn, J. (2006). Effects of Injury on the Locomotion of Free-Living Chimpanzees in the Budongo Forest Reserve, Uganda. Primates of Westerns Uganda, pp. 259-280.

Nakai, M. (2003). Bone and Joint Disorders in Wild Japanese Macaques from Nagano Prefecture, Japan. Int $J$ Primatol, 24(1), pp. 179-195.

Nakamichi, M. (1986). Behavior of Infant Japanese Monkeys (Macaca fuscata) with Congenital Limb Malformations during Their First Three Months. Developm Psychobiol, 19(4), pp. 335-341.

Nakamichi, M. et al. (1983). Behavioral Development of a Malformed Infant in a Free-ranging Group of Japanese Monkeys. Primates, 24(1), pp. 52-66.

Nakamichi, M. et al. (1997). Birth rate and mortality rate of infants with congenital limb malformations of the limbs in the Awajishima free-ranging group of Japanese monkeys (Macaca fuscata). Am J Primatol, 42, pp. $225-234$.

Ogihara, M. et al. (2005). Kinematic analysis of bipedal locomotion of a Japanese macaque that lost its forearms due to congenital malformation, Primates, 46, pp. 11-19.

Ohashi, G. y Matsuzawa, T. (2011). Deactivation of snares by wild chimpanzees, Primates, 52, pp. 1-5.

Oliver, M. (1998). ¿Una sociología de la discapacidad o una sociología discapacitada? En L. Barton (Comp.), Discapacidad y sociedad. Ediciones Morata.

OMS (2001). Clasificación Internacional del Funcionamiento de la Discapacidad y de la Salud. Organización Mundial de la Salud. https://apps.who.int/iris/bitstream/handle/10665/43360/9241545445_spa.pdf;jsessionid=15D CE84AF3DDFC839D21324EEAE2EA5A?sequence $=1$.

OMS (2011). Informe Mundial sobre la Discapacidad. Resumen. Organización Mundial de la Salud y Banco Mundial. https://www.who.int/disabilities/world_report/2011/es/.

Oxenham, M. F. et al. (2009). Paralysis and severe disability requiring intensive care in Neolithic Asia. Anthropological Science, 117(2), pp. 107-112. 
PAHO (2012). Capítulo 2. Determinantes e inequidades en salud. Pan American Health Organization. https://www. paho.org/salud-en-las-americas-2012/index.php?option=com_content\&view=article\&id=58:health-determinants-and-inequalities\&ltemid=165\&lang=es.

Pérez, M. E. y Chhabra, G. (2019). Modelos teóricos de discapacidad: un seguimiento del desarrollo histórico del concepto de discapacidad en las últimas cinco décadas. Revista Española de Discapacidad, 7(I), pp. 7-27.

Russell, Y. I. (2010). Third-party grooming in a captive chimpanzee group. Primates, 51, pp. 79-82.

Sayer E. C. et al. (2007). Who Needs a Forelimb Anyway? Locomotor, Postural and Manipulative Behavior in a One-Armed Gibbon. Zoo Biology, 26, pp. 215-222.

Seco, B. (S/f). Cuerpo, discapacidad, intimidad - Cuerpos diversos, otras miradas, otros sentidos. Blog del Proyecto de Tesis doctoral. https://cuerpodiscapacidadintimidad.wordpress.com/introduccion-2/.

Stokes, E. J. (1999). Feeding skills and the effect of injury on wild chimpanzees [Tesis doctoral, University of St Andrews].

Stokes, E. J. y Byrne R. W. (2001). Cognitive capacities for behavioural flexibility in wild chimpanzees (Pan troglodytes): the effect of snare injury on complex manual food processing. Animal Cognition, 4, pp. 11-28.

Stokes, E. J. y Byrne, R. W. (2006). Effect of Snare Injuries on the Fig-Feeding Behavior of Chimpanzees of the Budongo Forest, Uganda: Behavioral Adaptations and Long-Term Implications. Primates of Westerns Uganda, pp. 281-298.

Tokuyama, N. (2019). Snare-related disability led to the near-fatal accident of a bonobo at Wamba, Democratic Republic of the Congo. Pan Africa News, 26(1), pp. 7-9.

Struhsaker, T. T. et al. (2010). Healthy baboon with no upper jaw or nose: an extreme case of adaptability in the Kibale National Park, Uganda. Primates. https://doi.org/10.1007/s10329-010-0224-4.

Tilley, L. (2015). Chapter 8 Survival with Severe Disability: A Case of Long-Term Care in Neolithic Vietnam (Case Study 1). En L. Tilley, Theory and Practice in the Bioarchaeology of Care. Bioarchaeology and Social Theory. Springer.

Turner, S. E. (1999). Behavioral aspects of maternal investment and disabiity in mother and infant japanese macaques (Macaca fuscata) with congenital limb malformations [Tesis de Maestría, B.A. Simon Fraser University].

Turner, S. E. et al. (2005). Maternal Behavior and Infant Congenital Limb Malformation in a Free-Ranging Group of Macaca fuscata on Awaji Island, Japan. Int J Primatol, 26(6), pp. 1435-1457.

Turner, S. E. et al. (2008). Monkeys with disabilities: prevalence and severity of congenital limb malformations in Macaca fuscata on Awaji Island. Primates, 49, pp. 223-226.

Turner S. E. et al. (2012). Disability, compensatory behavior, and innovation in free-ranging adult female Japanese macaques (Macaca fuscata). Am J Primatol, 74(9), pp. 788-803.

Turner, S. E. et al. (2014). Social consequences of disability in a nonhuman primate. Hum Evol, 68, pp. 47-57.

Turner, S. E. et al. (2018). Disability and Dominance Rank in Adult Female and Male Japanese Macaques (Macaca fuscata). En U. Kalbitzer y K. M. Jack (Eds.), Primate Life Histories, Sex Roles, and Adaptability, Developments in Primatology: Progress and Prospects. https://doi.org/10.1007/978-3-319-98285-4_8

Wallace, A. R. (1958). On the Tendency of Varieties to Depart Indefinitely From the Original Type. Western Kentuky University, TopScholar Library Public Services, Alfred Russel Wallace Classic Writings [2009]. https://digitalcommons.wku.edu/cgi/viewcontent.cgi?article=1002\&context=dlps_fac_arw. 